\title{
On the way of liberation from suffering and pain: role of hypnosis in palliative care
}

\author{
Enrico Facco ${ }^{1,2}$, Edoardo Casiglia ${ }^{2,3}$, Gastone Zanette $^{2,4}$, Ines Testoni ${ }^{5}$ \\ ${ }^{1}$ Studium Patavium, University of Padua, Padua, Italy; ${ }^{2}$ Institute F. Granone - Italian Center of Clinical and Experimental Hypnosis (CIICS), Turin, \\ Italy; ${ }^{3}$ Department of Medicine, ${ }^{4}$ Department of Neurosciences, Chair of Dental Anesthesia, 5Department FISSPA, University of Padua, Padua, Italy \\ Contributions: (I) Conception and Design: E Facco; (II) Administrative support: None; (III) Provision of study materials or patients: None; \\ (IV) Collection and assembly of data: None; (V) Data analysis and interpretation: None; (VI) Manuscript writing: All authors; (VII) Final approval of \\ manuscript: All authors. \\ Correspondence to: Enrico Facco. Department of Neurosciences, Chair of Dental Anesthesia, University of Padua, Via Giustiniani 2, Padua 35128, \\ Italy. Email: enrico.facco@unipd.it.
}

\begin{abstract}
The huge problems related to chronic, ultimately fatal diseases involve disability, pain, suffering and the perception of one's doom; this calls for reappraising the conventional concepts of health and disease, life and death, encompassing spirituality and the mystery of death beyond any limited perspective. The management of suffering and pain to enhance resilience plays a central role in palliative care (PC) and is the core of the patient-centered approach, focused on the "to care" instead of the "to cure" of the illnesscentered medicine. In this article, the perspectives supporting these instances are analyzed, focusing on hypnosis, to be considered as a powerful technique able to improve patient's control over mind and body (including relaxation, fairness, analgesia, improved stability of physical parameters and wellbeing).
\end{abstract}

Keywords: Hypnosis; consciousness; anxiety; depression; pain; palliative care (PC); resilience

Submitted Jan 13, 2017. Accepted for publication Mar 09, 2017.

doi: 10.21037/apm.2017.04.07

View this article at: http://dx.doi.org/10.21037/apm.2017.04.07

\section{Introduction}

The great evolution of scientific knowledge and biotechnology in the late 20th century has led to a significant development of clinical medicine, strongly improving both the quality of life and the lifespan. Pain therapy and the pharmacological management of psychiatric disorders have paralleled the evolution of medical science, founded on a disease-centred approach according to the ruling mechanist-reductionist paradigm. On the other hand, it has led to patients being objectified, concealing their subjectivity and forgetting that both suffering and pain are a matter of subjective experience.

Despite the universally accepted definition of pain defines it as a psychosomatic experience and avoids tying it to the only stimulation of pain pathways (1), most of research and clinical practice have been centred on pain killers, adjuvant drugs (e.g., antidepressant) and invasive procedures, understating its subjective nature and patient's role in the management of suffering. Nevertheless, the latter is a key point in palliative medicine and end-of-life care, where suffering is closely related to the perception of one's doom. This is a huge and still unsolved problem of medical care endowed with several theoretical implications, including philosophical and psychological ones: in fact, resilience, cognition and metacognition cannot be relegated to a pharmacological manipulation only, as the reductionism progressively developed from the 17 th century implies (2). The shift from the concept of "to cure" to "to care" adopted by the palliative care (PC) endorses the patient-centred perspective, including both patient's viewpoint and resources as well as the huge ethical problems and dilemmas involved his/her management, a fact of paramount importance in severe diseases, like cancer, and the progression towards the end of life. On the other hand, the curative medicine does not seem ready to assume such a point of view and manage all its implications yet. The aim of this article is to appraise 
the problem, in order to show how hypnosis could offer a relevant support in $\mathrm{PC}$.

\section{Beyond death toward a new look on dying}

The concept of death is not strictly medical, but involves biological, cultural, philosophical, psychological, and religious implications. Its counterpart is the definition of life, the other side of the coin: despite all of us know and directly experience every day what life is, its definition is far from being simple. The scientific definitions of death and life are countless, because they are object of both philosophy and biology. In the interdisciplinary science of thanatology, two main areas of studies describe the most important directions in the explanation of the sense of death. The first one is inherent to the medical processes and is based on scientific reductionism, which does not provide a definition of what life and death mean (3); the second is focused on the symbolic questions engendered by the relationship between life and death $(3,4)$ and is aimed at analysing the explanations and the narration on this crucial existential issue. The success of the former is incessantly growing, thanks to the results of the medical science, but its foundation cannot be considered as the unique possible form of scientific explanation.

Life may be tentatively defined as anti-entropy, a huge, inseparable complex of energy-information, where the interchange with external environment (including energy and matter transfer) allows for keeping organization, development, reproduction. The energy-information is at the base of existence and maintenance of the physical body in its ceaseless transformation from conception to death, where the entropy passively increases following the entropy of the system one belongs to (5). From this point of view, life is considered as the integrating function of living organisms, the nature of which is not known but might be assigned to the world of energy, according to the concepts of philosophical tradition, ranging from the Aristotle's "entelechy" to Bergson's "élan vital", as well as the concept of Yin-Yang and Qi in Taoism. In fact, the theory of information defines information as negative entropy. It is a term introduced by the Nobel prize physicist Erwin Schrödinger (6) and later renamed "negentropy" by Léon Nicolas Brillouin [1889-1969; quoted by Boniolo (7)]: if the nature of information is negentropy, it also belongs to energy (related to the level of determination of a message). In this regard, it is worth noting that the essential feature of genetics and epigenetics, which lie at the foundation of physical life, is to drive information; the essential feature of mind is the management of information as well, while, according to Popper et al. (8), mind has also several properties common to physical forces. There is also an increasing evidence of the close relationship mind-body-environment based on the interrelationship between experience, behavior and epigenetics (9-11). If life can be conceived as negentropy and each living being is characterized by a ceaseless transformation, death is a relevant aspect of this transformation and, thus, is a feature of life rather than its irreconcilable opposite, even if this leads to the phenomenal appearance of the existence being lost forever.

Thus, death is an essential part of life, while it wrongly looks to be its awful opposite only from the naïve egocentric perspective of ordinary consciousness. The whole problem has been wisely defined by the great Taoist philosopher Zhuāngzĭ (4th century B.C.) as follows (12): "Life follows death and death is the forerunner of life. Who can know their ways? Human life begins with the original breath; when it comes together is life, when it is dispersed, there is death. As death and life are together in all this, which should be termed bad?". It is possible to start from this standpoint in order to offer a new look in meaning the life and death relationships, useful to improve resilience at the end of life.

\section{Health-disease and palliation}

According to Woodruff et al. (13), a disease can be defined as follows: "Any condition associated with discomfort, pain, disability, death, or an increased liability to these states, regarded by physicians and the public as properly the responsibility of the medical profession, may be considered a disease". In the progression from the onset to terminal state, the disease is considered more and more severe up to its terminal, untreatable stage. Facing severe diseases, the heroic nature of the curative medicine justified that the more severe was the disease the more aggressive the treatment, with the risk of doing it even in the case of no hope or a bad cost/ benefit ratio (from patient's perspective). For example, this is the main concern for extremely radical surgery, like hemicorporectomy, a questionable intervention introduced in the 60 s of last century, raising huge ethical and philosophical questions (14).

Granted the above mentioned concept of life-death, and following the acceptance of death as an inseparable part of life, the separation between curative and palliative medicine looks to be conventional rather than substantial, 
though practically valuable; it may partly be a by-product of the illusory denial of death and the objectivism, leading one to neglect patients' subjectivity (see below). Since we all are to die, health can be paradoxically defined as an asymptomatic disorder, inescapably leading one to death: if this is the case, health itself fulfills the above definition of disease by Woodruff et al. (13). As a result, health might be considered as the most insidious illness, since, being asymptomatic, no diagnosis is possible, letting one to skip his/her doom. This paradoxical definition of health allows to emphasize the physiology of life with its impermanence and how pain and other symptoms make one wake up and get aware of it, presenting one with his/her limits, the prospect of disability and death. As already mentioned, if individual life is impermanent death is neither the opposite of life nor its negation: it is an inseparable attribute of life in its phenomenal appearance and its ceaseless transformation. According to Epicurus, death does not exist in itself and, thus, the dread of death is unmotivated: "Death, therefore, the most awful of evils, is nothing to us, seeing that, when we are, death is not come, and, when death is come, we are not. It is nothing, then, either to the living or to the dead, for with the living it is not and the dead exist no longer" (Letter to Menoeceus).

When the above definition is admitted, the conventional concept of disease discloses an implicit denial of death as a part of life: we die just because we were born, rather than because of disease. Diseases are only different ways to pass away. Thanks to medicine, we can recover or improve the course of diseases, significantly postponing our death (its value is undeniable): thus, medicine provides us with living longer, the result of which is no more than altering the time and way of dying, not avoiding it.

\section{The management of death in medicine}

Physicians are traditionally not competent in death, apart from its diagnosis and the knowledge of thanatological changes of the corpse. It is not surprising since, by definition, death is beyond the boundaries of clinical interest; even more, it represents the failure of medicine tour court. Thus, the problem of death in medical science mainly regards the mechanisms by which others die, without any interest for its meaning and impact on patients' lives, in a context where a progressive dehumanization of care has occurred in the past decades. The ruling materialist-reductionist paradigm of scientific medicine, heir of logic positivism, has focused on mechanical aspects of dying only (the only ones looking relevant for their medical mechanistic manipulation) and skipped all what is not compatible with it, while the spirit of the time has led to a progressive denial of death itself, an event with no ostensible escape.

The Sigmund Freud sentence (paraphrasing a famous Latin motto on peace and war), "Si vis vitam, para mortem (I you wish life, prepare death)", emphasizes the need for accepting death to live better. On the other hand, in the positivist-materialist climate of early 20 th century he considered gods and the immortality of soul as a sort of "universal obsessional neurosis" (15), while Karl Marx defined it as the "Opium des Volkes (opiate of the masses)". This remains an axiomatic stance, a priori negating what is simply unknown without any demonstration of its inexistence (for further details on the limits and pitfalls of both materialistmonist and dualistic views, see $(16,17)$.

The psychological removal of death has been empirically analyzed by the terror management theory, according to which death anxiety is the product of the contradiction between the biological compulsion to survive and awareness of death (18-20). It is the key point of any cultural discussion and behavior leading to death being postponed, overcome or denied, including philosophical and religious views on immortality as well as medicine, science and technology, which also spring from the same powerful fear. Anyway, death anxiety is maladaptive (21) and the best solution, i.e., resilience, remains a matter for philosophy and religion, to be regarded as a true, valuable search of the meaning of life, rather than a clumsy, illusory attempt to relieve the terror only.

The neglect of death is an illusory response to the fear of death, rather than a well-founded, rational one, following the 20th century collapse of the idea of an afterlife beyond the physical one. In the ruling materialist view, it has led to what Gorer named "the pornography of deatb" (22). In fact, one is inadvertently inclined to refuse it as an obscene, unmentionable issue (like sex was in the past), while being at the same time greatly attracted by death (likewise sex), which remains omnipresent in our society (e.g., crime pages in mass media and movies).

Death was once a private affair, lived in the context of family with its cultural and religious meaning, while today the end of life has mostly become a matter of public policy, laws, bills and bioethical debate (including the issues of brain death, end of life decision making, advance directives, surrogate decisions). Therefore, it is managed in the hospital setting, approached from a technical perspective 
and mainly managed according to an ethnocentric, parochial perspective (23). But death and dying are far from being a plain technical-scientific-political problem to be managed with organizational criteria only: it is a huge, individual, subjective problem closely linked to culture, tradition, philosophy and religion (24).

The view of life does not only affects the perception of death, but also makes the same way of dying as desirable or fearsome, being such the power of culture and beliefs that it may even turn the same facts upside down. For example, at the present time everyone would like to die as late as possible by sudden death (i.e., a cardiac arrest in full wellbeing, without suffering and perceiving one's end), rather than from chronic diseases and a long agony. Conversely, in the past centuries the former was the most feared way of dying, since it prevented to prepare and, thus, save oneself in the afterlife: in Catholic tradition, this is clearly shown by the figure of St. Andrews (Andrea) Avellino, the patron saint of Naples (together with Saint Gennaro) and Sicily, who was especially invoked against the sudden death.

In short, the materialist scientific representation of humanity is founded on the belief that afterlife and immortality are a myth and men are doomed to die despite their self-awareness, meant as a simple by-product of brain circuitry. Anyway, this stance, though plausible, is axiomatic, and, as such, is not demonstrated: thus, the denial of anything beyond the physical, outer world as it looks in its phenomenal appearance remains an arbitrary choice of sides, rejecting it a priori without proofs of its nonexistence. It belongs to the endless, still unsolved debate between materialist-monists and dualists involved in the philosophical speculation on life and death (and the related actual debate between presentism and eternalism) $(17,25)$, in the scientific interpretation of near-death experiences $(5,26,27)$ as well as the foundation of the science of consciousness (16,28). Furthermore, dying and its related experiences, i.e., near-death and end-of-life experiences, also lie in the ticklish area where the competence of science, philosophy and religion converge and traditionally clash, due to century old prejudices (i.e., the boundaries between the physical reality, as we perceive it, and hereafter whatever it might be, including annihilation). The border is, by definition, the limit of competence of science, while its crossing is the inescapable, real adventure of the dying, a matter no less relevant and concrete than the management of physical and psychological symptoms. Again, this calls for reintroducing philosophy as a helpful resource of knowledge and resilience in the care of advanced and terminal patients, with the following three general criteria:

(I) To carefully tell what is simply unknown from what is non-existent, in order to avoid the risk of falling into a kind of scientific or religious dogmatism;

(II) To avoid the inclination to intentionally provide illusory comfort by feeding false beliefs in the attempt to relieve death anxiety;

(III) To favor an open-minded approach to the real mystery of human life from a meta-philosophical and meta-religious perspective $(5,16,27,28)$, free from any prejudice of whatsoever origin. This may turn the distressing tragedy of death and annihilation into the most meaningful, concrete philosophical problem and mystery of our apparent doom, which can only be solved by trespassing the gate of death.

If this is the case, death is no longer a tragedy; rather, it might be the most important event of life, the only one allowing to achieve the unattainable truth, precluded during life. As the great Sufi mystic Ibn 'Arabi stated, "Life is like a waking dream, from which one wakes up at the point of death" $(28,29)$. It is just the opposite but does not seem less plausible than the Hamlet' reflection (Act 3, Scene 1), better fitting the western perspective: "To be, or not to be? That is the question... To die, to sleep—no more—and by a sleep to say we end... To die, to sleep. To sleep, perchance to dream". Anyway, whatever the solution of this endless human dilemma, it suggests the need to die with one's eyes open, according to the Roman emperor Hadrian in the Marguerite Yourcenar's fiction (30).

\section{The ill-founded separation between curative and palliative medicine}

The ruling mechanist-reductionist paradigm of medical science mainly springs form the result of Descartes's thought, Enlightenment, empiricism and positivism, which have progressively focused the interest on the external, objective, physical reality. This stance has been pragmatically valuable, in that it allowed for an outstanding development of modern science. On the other hand, the birth of the new sciences has been flawed by an original sin, i.e., the result of a political compromise between the 17 th century rationalistic revolution and Inquisition, rather than from a free philosophical reflection on what and how should be investigated. The new sciences were forced to a priori disregard consciousness and soul, of exclusive competence 
of the Church and theology, and devoted themselves to the mathematic, quantitative, mechanistic analysis of the physical world only $(16,27,28)$. This was possible thanks to the Descartes' split of res cogitans (consciousness and soul) and res extensa (the body and the physical world), allowing medicine to deal with the Cartesian earthen body machine only, safe from Inquisition but wrongly leading to consciousness being disregarded, as if the role of mind would be irrelevant in both health and disease. The birth of the modern, scientific psychology in late 19th century and of the science of consciousness in the latter 20th century are the consequence of this strong cultural long-lasting filter (16).

The paradigm of the scientific medicine is focused on organic diseases, neglecting the mind-body relationship. As a result, the ruling approach of modern medicine is strongly inclined to treat the disease, rather than the patient, while he/she is generally considered as a mere passive carrier of it, rather than an active moving force in both pathophysiology and recovery. Despite its recognized power, the nature and etiology of most diseases is still unknown, somehow making their diagnosis a conventional fact, a noun attached to a wider and often only partly known process (31). Furthermore, many diseases do not depend on biological components only, but involve relevant psychosomatic factors, the role of which is relevant in many disorders, such as the so-called medical unexplained physical symptoms $(16,32,33)$; psychosomatic components are probably involved in many other organic diseases as cofactors of their pathophysiology or as patients' reactions able to alter the clinical course, such as in the case of heart failure (34-36).

In short, the paradigm of modern medicine has obtained outstanding results in the management of the physical components of disease, but has denied the role of patients' subjectivity in both pathophysiology and healing, alienating them from doctors transformed in cold technicians; the parallel illusory denial of death and the increasingly aggressive interventions have helped inadvertently increasing suffering.

In 1948 the World Health Organization (WHO) in its Constitution (37) has wisely defined health as " $A$ state of complete physical, social and emotional well-being, and not merely the absence of disease or infirmity". This has led to the emergence of the concept of positive health (i.e., living well rather than living long only), in order to fill the gap between the totality of health and the limited aspect of disease. This has been paralleled by the perceived relevance of the patient as a person (not a plain carrier of disease), his/her dignity and resilience in the psycho-existential dimension, including spirituality (38). Both the World Psychiatric Association (WPA) and the WHO have recently recognized the relevance of spirituality and religion in mental health as well as quality of life, while WPA and several national psychiatric associations have created sections on spirituality and religion (39). The concept of spirituality, despite still ill-defined, may be approached by a secular point of view and reintroduced in the world of science by recognizing its nature of faculty of mind, in itself independent from any church (16).

PC was born in the eighties of last century to take care of patients not responsive to curative therapy and has progressively extended its interest from the terminal ones to the early stages of any chronic, ultimately fatal illness; likewise, the initial focus on pain has been extended to all other component of patient's suffering, including physical, emotional, and spiritual needs of the patient and, then, to family members, and care givers (40). This relevant evolution of $\mathrm{PC}$ reflects new needs posed by patients and by the increased power and limits of curative medicine.

PC was initially considered as a son of a minor god, devoted to relieve pain but unable to cure patients. On the other hand, one is to wonder whether PC should be considered as a field of medicine to be kept as distinct from mainstream medicine or, rather, its birth reflects the limits and pitfalls of the mechanistic approach of the curative one, unable to take care of the person of patients. According to the WHO's concept of health, a mechanistic approach only able to treat organic lesions of the body is far from being enough: instead, medicine is and should be only one, able to respond to all patients' needs, both physical and psychological, objective and subjective, with their inescapable environmental interrelationship. This is in line with the Hippocrates' holistic teaching, well-shaped by Plato: "Hippocrates the Asclepiad says that the nature even of the body can only be understood as a whole" (Phaedrus, 270b-e). It included the concepts of o $\lambda$ ov $\varphi v \sigma \varepsilon \circ \zeta$, (oloi physeos, the whole)

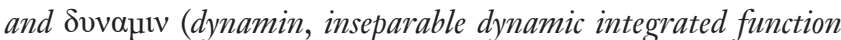
of mind-body-environment), betrayed by an unyielding reductionist approach (41).

\section{Hypnosis}

Hypnosis, clearly belonging to the world of subjectivity and experience, has been misunderstood and a priori rejected since its introduction in 18th century, when it was named mesmerism from the name of its founder Franz Anton 
Mesmer [see (28), for a detailed analysis of the history, phenomenology of hypnosis and related prejudices]. The old prejudices on its nature still persist in general population and health professionals, fed by stage hypnotists claiming that hypnotized subjects lose their voluntary control and get owned by their power. Instead, hypnosis is just the opposite: it is not a matter of "power" of the hypnotists or something one person does to another, but an ability that one person can identify and teach to another. Hypnotic induction is an occasion to assess and utilize subject's hypnotic ability, enabling him/her to restructure the understanding of a problem and control functions not manageable with ordinary consciousness and will: therefore, it must be regarded as valuable tool for subject's empowerment, allowing to achieve goals normally precluded.

Two key points of hypnosis are the focalization of attention and absorption, leading to a deep insight and yielding the so-called plastic mono-ideism (i.e., an idea lived as if it were real with all sensory and neurovegetative changes). This in turn allows for an enhanced intentional control of both psychicological and physical functions, giving rise to a wide range of phenomena, such as deep relaxation, analgesia, and specific hemodynamic changes (28,42-48). Absorption is defined as a total attention fully engaging one's representational resources and, thus, excluding distracting events from perception; it also involves an openness to absorbing and self-altering experiences (49). The personality features of hypnotizability, i.e., the capacity to experience a transition into a hypnotic state and perform hypnotic tasks, are not fully understood yet. Some relationship between hypnotizability and absorption, dissociative experiences, proneness to fantasy, reaction time in a go/no-go task, proneness to trust, emotional flexibility, sensitivity and empathy seems to exist (50-60); other features, like expectation, imagery, empathy, trust and ability to manage attentional resources might be involved as well (61-66).

Hypnosis is a very manageable and fast technique, making it suitable for the use in both medical and surgical setting. For example, in the context of perioperative care the induction of hypnosis it calls for 1-3 min only. Its deepening and the delivery of all suggestions needed to get a full relaxation, increase of pain threshold (up to surgical analgesia in patients able to do it), the detachment from the operating room and the deep immersion in a pleasant, safe place calls for no more than $5-10 \mathrm{~min}$. This makes it no more time consuming than a pharmacological sedation (67).

A relevant advantage of hypnosis is that patients can learn to use self-hypnosis to manage their problem in full autonomy, be they psychological or physical, i.e., to decrease or withdraw anxiety, pain, induce sleep, or face previously feared therapies (like chemo- or radiotherapy) in full relaxation and tranquility.

Self-hypnosis has a strong link with meditation techniques, including historical, procedural and neuropsychological aspects, while both of them were borne and used tool to enhance resilience and relieve suffering and pain since their introduction. It is worth noting that ancient mesmerists were strongly interested eastern healing techniques, while Buddhism stemmed from Siddharta Gautama observation of the omnipresence of pain and suffering along life, their origin in ordinary consciousness and, thus, their relief through a rationally sound mental activity [see $(28,68)$ as reviews]. On the other hand, meditation calls for a long training and can be regarded as a long lasting philosophical way towards the liberation from suffering and pain, while hypnosis can be used to get much stronger and faster effect in a pragmatic, though more limited, clinical setting. Hypnosis is also superior to other behavioral techniques (e.g., empathic communication), which have been used for control groups in randomized prospective trials on hypnosis in perioperative care (67).

Both hypnosis and meditation are far from being simple, monomorphic activities. What is more standardizable is the formal procedure, i.e., the induction, deepening and dehypnotization, while a wealth of instructions, suggestions and metaphors is available to fit to the wide range of patients' needs, from psychological to physical ones. They may involve very different targets, such as strengthening of the ego, change of perspective towards their problems and their restructuring, relieve physical and/or psychological symptoms like anxiety and pain, or specific symptoms related to different organs (e.g., constipation or diarrhea, dyspnea, functional heart disorders, insomnia etc.). The common trait of all-them is the kind of communication, based on imagines and metaphors, which help patients living and feeling what is communicated with a psychosomatic participation, a tool totally different from the ruling logicalanalytic, cold, intellectual communication usually adopted. To live and to feel, instead of only rationally understand, helps one's transformation, or better trance-formation, to use Spiegel's words (48), enhancing the adoption and implementation what is experienced, if considered valuable: in this regard, conventional communication and hypnosis may be compared to lectures and simulator training in teaching, respectively. Finally, hypnosis may also be 
used indirectly, according to Milton Erickson, without a formal induction and deepening, but using hypnotic communication during a visit (69), outside its use for invasive procedures and other special needs.

Given its wide range of instructions and targets, the neuropsychological aspects of hypnosis, i.e., the patterns of activation and deactivation of brain areas, vary accordingly and their analysis is far beyond the aims of this article [see $(28,67,68,70-74)$ as reviews]. Here, it is only worth mentioning that hypnosis has been proven to yield specific changes in several brain areas and circuits, according to the aims of delivered suggestions, such as changes of activation and connectivity of pain neuromatrix, default mode network and extrinsic system $(72,73,75-82)$.

\section{Role of hypnosis in PC}

Given the wide range of possible indications, hypnosis is a valuable candidate for a central role in PC, where it can be used to manage both psychological and physical symptoms as well as specific interventions. Only a handful of papers is present in PubMed when "hypnosis" and "palliative care" are used as keywords (83-86), while several studies on its use in the management of cancer patients are available since the sixties of last century, when the term palliative medicine had not been introduced yet. Part of the published studies deals with hypnosis for invasive procedures and surgery and will not be discussed here, since they belong to the field of anesthesia, rather than disease related symptoms, and have been already reviewed elsewhere (67).

A systematic review on hypnosis in breast cancer has reported a promising evidence of the effectiveness of hypnosis in breast cancer care (87). A $68 \%$ reduction of flashes, anxiety and depression as well as improved sleep has been reported in a randomized controlled study (RCT) (88), while an increase in natural killer cell count (89), pain and fatigue (90-92) have been reported by other authors. An RCT reported a significantly less increase in the intensity of pain and suffering over 12 months compared to the control group, with no relationship with hypnotizability; however, highly hypnotizable participants reported greater benefits and employed self-hypnosis more often to manage other symptoms in addition to pain (93). Nausea and vomiting, be it anticipatory or related to the adverse effects of chemotherapy, are effectively relieved by hypnosis as well $(94,95)$.

A few studies suggest that psychological interventions and/or hypnosis might reduce the rate of relapse and increase survival in both breast and lung cancer [see (48) as a review]. Despite there is no clear evidence yet, the possibility and plausibility of improving survival through psychosomatic interventions affecting the bodily regulation at the neurovegetative, endocrine, epigenetic and/or immune levels is intriguing and deserves further study.

Figure 1 shows a tentative, provisional flowchart of the use of hypnosis and its targets in the management of PC, the main aspects of which are the following:

(I) Perioperative care [see (67) as a review], including: (i) a cognitive approach to properly face surgery plus relaxation to relieve preoperative anxiety and concern; (ii) sedation for surgery and invasive procedures (alone or associated to local or general anesthesia); (iii) postoperative management of pain, discomfort, physical parameters, nausea and vomit.

(II) Management of acute and chronic pain.

(III) Management of anxiety and depression.

(IV) Management of nausea and vomiting, and other symptoms (e.g., constipation, diarrhea, fatigue, dyspnea, insomnia).

(V) Resilience.

The whole of the above-mentioned uses of hypnosis includes a wealth of possible, specific suggestions and metaphors, the detailed description of which is far beyond the available space and aims of an article. The wide range of possible uses of hypnosis in PC shown in Figure 1 covers the whole clinical course from the first diagnosis to the terminal phase. The approach to resilience, which has a special role in the field of PC, can be synthetically divided into two main components:

(I) A philosophical, metacognitive approach to patient's problem, which must take into in account all his/her concerns and worries and help finding a proper interpretation and possible solution, even in the case of a bad short-term outcome. The relief from pain and suffering and improved wellbeing are factors of paramount importance to be managed with behavioural techniques, since the nocebo effect, springing from a bad doctorpatient relationship and communication, may yield hyperalgesia and allodynia, decreased quality of life, lower the adherence to therapy, and increased anxiety (96-100). It is not a matter for hypnosis only; rather, it calls for an appropriate behaviour of all caregivers and a rational, meaningful 


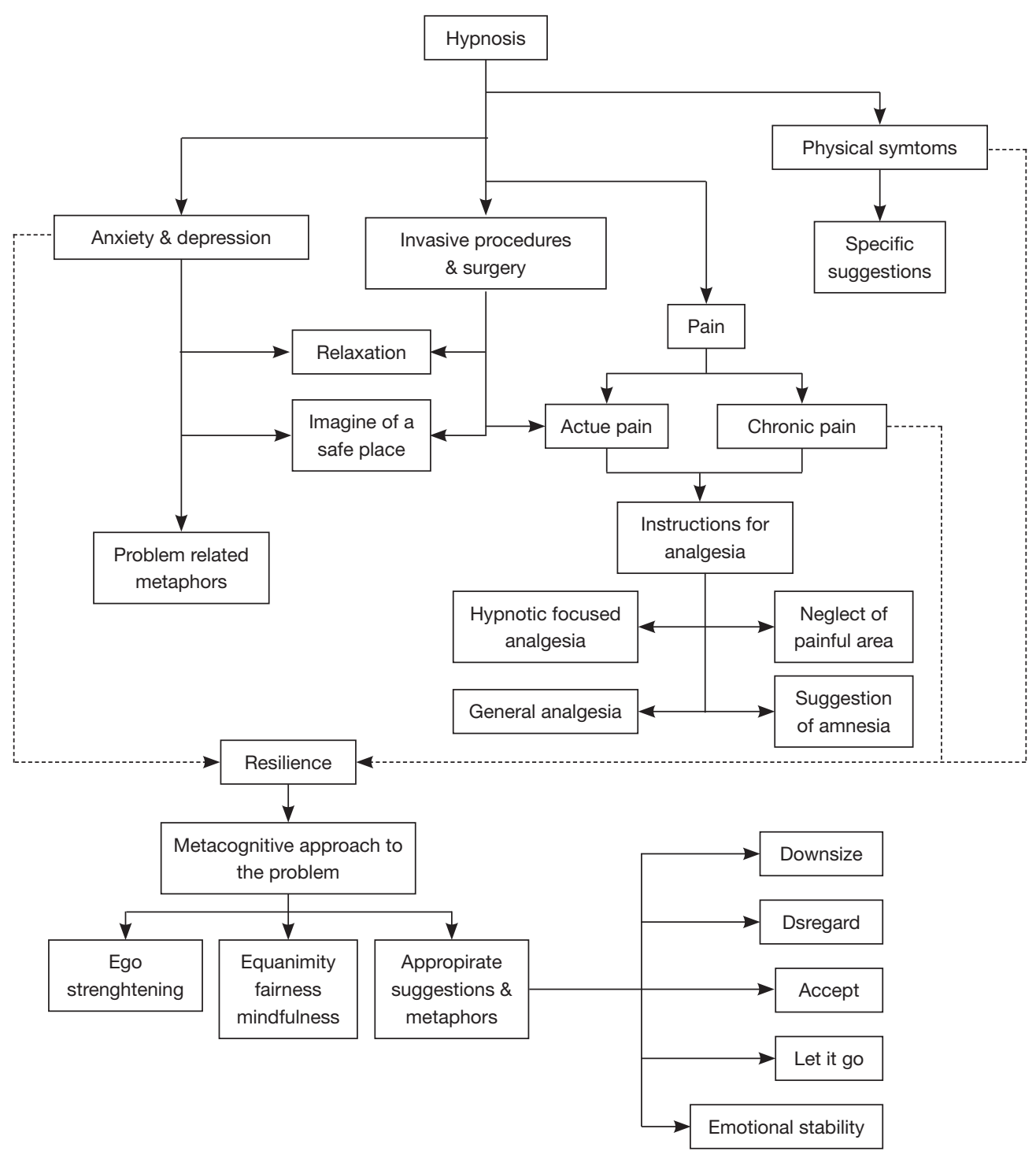

Figure 1 Tentative, provisional flowchart of the role of hypnosis and its main therapeutic targets in palliative care. Resilience is a relevant common aspect of the therapeutic strategy, involving a shared, meaningful, metacognitive approach to life, disease and its outcome as well as specific suggestions on the appropriated attitude and behavior.

philosophical approach able to share patient's view, experience and source of suffering. Hypnosis, used with formal induction or Ericksonian approach, may play a relevant role in helping patient's coping through a correct interpretation of his/her problem and appropriate behaviour.

(II) Specific metaphors and suggestions to strengthen the ego (when needed) and develop equanimity, fairness and mindfulness as well as help accepting one's conditions, downsizing and disregarding what is the cause of worry and negative emotions.

Resilience is a wide concept, to be regarded as the common path of all other hypnotic interventions for specific targets in PC, since it is related to suffering as a whole and is essential to properly face each phase of the clinical course. It is a concept drawn from physics, where it is defined as the property of an object of being able to recoil or spring back into a shape after bending. When a person is regarded, it means being able to withstand or recover quickly from difficult conditions (3), be the adversities related to family and social 
relationships, health, workplace, financial stressors etc. It involves the ability to make realistic plans and follow through with them, positive self-concept and confidence in one's strengths and abilities, problem-solving skills and ability to manage strong impulses and feelings.

Resilience strongly depends on culture, values and psycho-social factors and can be considered as a dynamic process rather than a trait, anyway depending on subject's capacity of restructuring problems and transforming him/herself to cope with life. This definition shows how resilience has huge, inescapable philosophical implications, since philosophy is the search of truth and the rational attempt to grasp the nature of reality, the meaning of life and death since time immemorial. Therefore, the first part of this article should not be only regarded as an abstract introductory speculation on life, disease and death but, rather, as a concrete, pragmatic reflection on the most crucial, unsolved problems of patients with severe diseases, facing the spectre of chronic pain, disability, invasive treatments and death. Of course, its aim is only providing some hopefully helpful clues for a reflection on the concrete, clinically relevant philosophical aspects of patient care and the development of an effective communication, including hypnotic suggestions and metaphors.

\section{Conclusions}

PC was introduced in latter 20th century as a minor field of medicine, able to relive pain but impotent to cure patients. Its outstanding evolution in recent years, extending its role to all patients' and relatives' needs since the early stage of any ultimately fatal illness, reflects the limits and pitfalls of the paradigm of the mainstream medicine, able to treat diseases but unable to take care of patients. There is an increasing need to reintroduce subjectivity in science and, in medicine, to reintroduce the patient and his/her mind as an inescapable moving force in both pathophysiology and therapy: this is the only way to rebuild a truthful, rational Hippocratic medicine, which has been betrayed by the mechanist-reductionist approach, a by-product of the western philosophical evolution from Enlightenment through materialism and logic positivism. Hypnosis (as well as meditation, given its strong links with hypnosis) is a valuable technique, able to give back the patient his/her power of control over mind and body, denied by mechanistic medicine, and improve resilience; therefore, it may play a central role in the management of pain and suffering, be it helped by pharmacological and interventional procedures.

\section{Acknowledgements}

None.

\section{Footnote}

Conflicts of Interest: The authors have no conflicts of interest to declare.

\section{References}

1. Merskey H. Logic, truth and language in concepts of pain. Qual Life Res 1994;3 Suppl 1:S69-76.

2. Russell B, Wisdom of the West. Foulkes P. editor. London: Rathbone, 1959.

3. Concise Oxford English Dictionary. 11th ed. New York: Oxford University Press, 2008.

4. Hornby AS, Cowie AP, Gimson AC. Oxford Advanced Lerner's Dictionary of Current English. Oxford: Orford University Press, 1974.

5. Facco E. Esperienze di premorte. Scienza e coscienza ai confini tra fisica e metafisica. Lungavilla (PV): Edizioni Altravista, 2010.

6. Schroedinger E. What is Life? The Physical Aspect of the Living Cell. Cambridge: Cambridge University Press, 1944.

7. Boniolo G. Aspetti epistemologici dello spazio e del tempo, 1987.

8. Popper KR, Lindahl BI, Arhem P. A discussion of the mind-brain problem. Theor Med 1993;14:167-80.

9. Curley JP, Jensen CL, Mashoodh R, et al. Social influences on neurobiology and behavior: epigenetic effects during development. Psychoneuroendocrinology 2011;36:352-71.

10. Mehler MF. Epigenetic principles and mechanisms underlying nervous system functions in health and disease. Prog Neurobiol 2008;86:305-41.

11. Puckett RE, Lubin FD. Epigenetic mechanisms in experience-driven memory formation and behavior. Epigenomics 2011;3:649-64.

12. The Book of Chuang Tzu. London: Penguin books, 2006.

13. Woodruff RA Jr, Guze SB, Clayton PJ. Psychiatric illness and season of birth. Am J Psychiatry 1974;131:925-6.

14. Jankowski J, Campo-Engelstein L. A better half: the ethics of hemicorporectomy surgery. J Bioeth Inq 2014;11:289-94.

15. Freud S. The Future of an Illusion. Seattle: Pacific Publishing Studio, 2010.

16. Facco E, Lucangeli D, Tressoldi P, et al. On the Science of Consciousness: Epistemological Reflections and Clinical Implications. Explore (NY) 2017. [Epub ahead of print].

17. Severino E. The Essence of Nihilism. NY: Verso Books, 2016. 
18. Greenberg J, Koole S, Pyszczynski T. Handbook of experimental existential psychology. New York: Guilford Press, 2004.

19. Pyszczynski T, Greenberg J, Solomon S. A dual-process model of defense against conscious and unconscious deathrelated thoughts: an extension of terror management theory. Psychol Rev 1999;106:835-45.

20. Greenberg J, Kosloff S. Terror management theory: Implications for understanding prejudice, stereotyping, intergroup conflict, and political attitudes. Soc Personal Psychol Compass 2008;2:1881-94.

21. Pyszczynski T, Greenberg J, Solomon S, et al. On the unique psychological import of the human awareness of mortality: Theme and variations. Psychological Enquiry 2006;17:328-56.

22. Gorer G. The pronography of death. In: Shneidmen ES, editor. Death: Current Perspectives. Palo Alto: Mayfield, 1976:(71-6).

23. Blank RH. End-of-life decision making across cultures. J Law Med Ethics 2011;39:201-14.

24. Harrison S, Moran M, Wood B. Policy Emergence and Policy Convergence: The Case of 'Scientific-Bureaucratic Medicine' in the United States and United Kingdom. J of Politics and International Relations 2002;4(1):1-24.

25. Loux MJ, Zimmerman DW. The Oxford Handbook of metaphysics. Oxford: Oxord University Press, 2000.

26. Facco E, Agrillo C. Near-death experiences between science and prejudice. Front Hum Neurosci 2012;6:209.

27. Facco E, Agrillo C, Greyson B. Epistemological implications of near-death experiences and other nonordinary mental expressions: Moving beyond the concept of altered state of consciousness. Med Hypotheses 2015;85:85-93.

28. Facco E. Meditazione e Ipnosi tra neuroscienze, filosofia e pregiudizio. Lungavilla: Altravista, 2014.

29. Izutsu T. Sufismo e Taoismo. Milano: Mimesis Edizioni, 2010.

30. Yourcenar M. Memoirs of Hadrian. New York: Farrar, Straus and Giroux, 2005.

31. Berganza CE, Mezzich JE, Pouncey C. Concepts of disease: their relevance for psychiatric diagnosis and classification. Psychopathology 2005;38:166-70.

32. Hausteiner C, Bornschein S, Zilker T, et al. Dysfunctional cognitions in idiopathic environmental intolerances (IEI)--an integrative psychiatric perspective. Toxicol Lett 2007;171:1-9.

33. Richardson RD, Engel CC Jr. Evaluation and management of medically unexplained physical symptoms. Neurologist
2004;10:18-30.

34. Carney RM, Freedland KE, Steinmeyer BC, et al. Clinical predictors of depression treatment outcomes in patients with coronary heart disease. J Psychosom Res 2016;88:36-41.

35. Moser DK, Arslanian-Engoren C, Biddle MJ, et al. Psychological Aspects of Heart Failure. Curr Cardiol Rep 2016;18:119.

36. Tully PJ, Winefield HR, Baker RA, et al. Confirmatory factor analysis of the Beck Depression Inventory-II and the association with cardiac morbidity and mortality after coronary revascularization. J Health Psychol 2011;16:584-95.

37. World Health Organization. International Classification of Functioning, Disability and Health (ICF). Geneva: WHO, 1948.

38. Mezzich JE. Positive health: conceptual place, dimensions and implications. Psychopathology 2005;38:177-9.

39. Moreira-Almeida A, Sharma A, Van Rensburg BJ, et al. WPA position statement on spirituality and religion in psychiatry. World Psychiatry 2016;15:87-8.

40. Sepúlveda C, Marlin A, Yoshida T, et al. Palliative care: the World Health Organization's global perspective. J Pain Symptom Manage 2002;24:91-6.

41. Lopez F. Il pensiero olistico di Ippocrate. S. Giovanni in Fiore (CS): Pubblisfera, 2004.

42. Casiglia E, Mazza A, Ginocchio G, et al. Hemodynamics following real and hypnosis-simulated phlebotomy. Am J Clin Hypn 1997;40:368-75.

43. Casiglia E, Rossi A, Tikhonoff V, et al. Local and systemic vasodilation following hypnotic suggestion of warm tub bathing. Int J Psychophysiol 2006;62:60-5.

44. Casiglia E, Schiavon L, Tikhonoff V, et al. Hypnosis prevents the cardiovascular response to cold pressor test. Am J Clin Hypn 2007;49:255-66.

45. Casiglia E, Tikhonoff V, Giordano N, et al. Measured outcomes with hypnosis as an experimental tool in a cardiovascular physiology laboratory. Int J Clin Exp Hypn 2012;60:241-61.

46. Facco E, Casiglia E, Masiero S, et al. Effects of hypnotic focused analgesia on dental pain threshold. Int J Clin Exp Hypn 2011;59:454-68.

47. Facco E, Pasquali S, Zanette G, et al. Hypnosis as sole anaesthesia for skin tumour removal in a patient with multiple chemical sensitivity. Anaesthesia 2013;68:961-5.

48. Spiegel D. Tranceformations: hypnosis in brain and body. Depress Anxiety 2013;30:342-52.

49. Tellegen A, Atkinson G. Openness to absorbing and self- 
altering experiences ("absorption"), a trait related to hypnotic susceptibility. J Abnorm Psychol 1974;83:268-77.

50. Balthazard CG, Woody EZ. The spectral analysis of hypnotic performance with respect to "absorption". Int J Clin Exp Hypn 1992;40:21-43.

51. Council JR, Green JP. Examining the absorptionhypnotizability Link: the roles of acquiescence and consistency motivation. Int J Clin Exp Hypn 2004;52:364-77.

52. Dienes $Z$, Brown E, Hutton S, et al. Hypnotic suggestibility, cognitive inhibition, and dissociation. Conscious Cogn 2009;18:837-47.

53. Frankel FH. Hypnotizability and dissociation. Am J Psychiatry 1990;147:823-9.

54. Green JP. Hypnotizability, the dissociative experiences scale, HGSHS: A amnesia, and automatic writing: is there an association? Int J Clin Exp Hypn 1997;45:69-80.

55. Green JP, Council JR. Does the positive keying of the TAS inflate the absorption-hypnotizability link? Int J Clin Exp Hypn 2004;52:378-88.

56. Green JP, Green ES. Predicting animal attachment from hypnotizability, absorption, and dissociation scores. Am J Clin Hypn 2010;52:205-18.

57. Wickramasekera IE 2nd, Szlyk JP. Could empathy be a predictor of hypnotic ability? Int J Clin Exp Hypn 2003;51:390-9.

58. Zachariae R, Jørgensen MM, Christensen S. Hypnotizability and absorption in a Danish sample: testing the influence of context. Int J Clin Exp Hypn 2000;48:306-14.

59. Spiegel H, Spiegel D. Trance and Treatment. 2nd ed. Arlington: American Psychiatric Press, 2004:(281-82).

60. Spiegel D. Minding the body: psychotherapy and cancer survival. Br J Health Psychol 2014;19:465-85.

61. Kirenskaya AV, Novototsky-Vlasov VY, Chistyakov AN, et al. The relationship between hypnotizability, internal imagery, and efficiency of neurolinguistic programming. Int J Clin Exp Hypn 2011;59:225-41.

62. Laurence JR, Beaulieu-Prévost D, du Chéné T. Measuring and understanding individual differences in hypnotizability. The Oxford Handbook of Hypnosis. New York: Oxford University Press, 2008(225-53).

63. Müller K, Bacht K, Prochnow D, et al. Activation of thalamus in motor imagery results from gating by hypnosis. Neuroimage 2013;66:361-7.

64. Rossi EL, Rossi KL. The neuroscience of observing consciousness \& Mirror neurons in therapeutic hypnosis. Am J Clin Hypn 2006;48:263-78.
65. Wickramasekera IE. Empathic features of absorption and incongruence. Am J Clin Hypn 2007;50:59-69.

66. Facco E, Testoni I, Ronconi L, et al. Psychological Features of Hypnotizability: A First Step Towards Its Empirical Definition. Int J Clin Exp Hypn 2017;65:98-119.

67. Facco E. Hypnosis and anesthesia: back to the future. Minerva Anestesiol 2016;82:1343-56.

68. Facco E. Meditation and Hypnosis: Two Sides of the Same Coin? Int J Clin Exp Hypn 2017;65:169-88.

69. Erickson BA. Eriksonian Hypnotherapy. In: Elkins GR, editor. Handbook of Medical and Psychological Hyponosis.New York: Springer Publishing Company, 2017(119-31)

70. De Benedittis G. Neural mechanisms of hypnosis and meditation. J Physiol Paris 2015;109:152-64.

71. Faymonville ME, Boly M, Laureys S. Functional neuroanatomy of the hypnotic state. J Physiol Paris 2006;99:463-9.

72. Rainville P, Hofbauer RK, Bushnell MC, et al. Hypnosis modulates activity in brain structures involved in the regulation of consciousness. J Cogn Neurosci 2002;14:887-901.

73. Rainville P, Price DD. Hypnosis phenomenology and the neurobiology of consciousness. Int J Clin Exp Hypn 2003;51:105-29.

74. Vanhaudenhuyse A, Laureys S, Faymonville ME. Neurophysiology of hypnosis. Neurophysiol Clin 2014;44:343-53.

75. Deeley Q, Oakley DA, Toone B, et al. Modulating the default mode network using hypnosis. Int J Clin Exp Hypn 2012;60:206-28.

76. Demertzi A, Soddu A, Faymonville ME, et al. Hypnotic modulation of resting state fMRI default mode and extrinsic network connectivity. Prog Brain Res 2011;193:309-22.

77. Demertzi A, Vanhaudenhuyse A, Noirhomme Q, et al. Hypnosis modulates behavioural measures and subjective ratings about external and internal awareness. J Physiol Paris 2015;109:173-9.

78. Derbyshire SW, Whalley MG, Stenger VA, et al. Cerebral activation during hypnotically induced and imagined pain. Neuroimage 2004;23:392-401.

79. Faymonville ME, Roediger L, Del Fiore G, et al. Increased cerebral functional connectivity underlying the antinociceptive effects of hypnosis. Brain Res Cogn Brain Res 2003;17:255-62.

80. Rainville P, Hofbauer RK, Paus T, et al. Cerebral mechanisms of hypnotic induction and suggestion. J Cogn 
Neurosci 1999;11:110-25.

81. Röder CH, Michal M, Overbeck G, et al. Pain response in depersonalization: a functional imaging study using hypnosis in healthy subjects. Psychother Psychosom 2007;76:115-21.

82. Vanhaudenhuyse A, Boly M, Balteau E, et al. Pain and non-pain processing during hypnosis: a thulium-YAG event-related fMRI study. Neuroimage 2009;47:1047-54.

83. Brugnoli MP. Clinical hypnosis for palliative care in severe chronic diseases: a review and the procedures for relieving physical, psychological and spiritual symptoms. Ann Palliat Med 2016;5:280-97.

84. Desai G, Chaturvedi SK, Ramachandra S. Hypnotherapy: fact or fiction: a review in palliative care and opinions of health professionals. Indian J Palliat Care 2011;17:146-9.

85. Elkins G, Fisher W, Johnson A, et al. Clinical hypnosis for the palliative care of cancer patients. Oncology (Williston Park) 2012;26:26-30.

86. Marcus J, Elkins G, Mott F. A model of hypnotic intervention for palliative care. Adv Mind Body Med 2003;19:24-7.

87. Cramer H, Lauche R, Paul A, et al. Hypnosis in breast cancer care: a systematic review of randomized controlled trials. Integr Cancer Ther 2015;14:5-15.

88. Elkins G, Marcus J, Stearns V, et al. Randomized trial of a hypnosis intervention for treatment of hot flashes among breast cancer survivors. J Clin Oncol 2008;26:5022-6.

89. Hudacek KD. A review of the effects of hypnosis on the immune system in breast cancer patients: a brief communication. Int J Clin Exp Hypn 2007;55:411-25.

90. Jensen MP, Gralow JR, Braden A, et al. Hypnosis for symptom management in women with breast cancer: a pilot study. Int J Clin Exp Hypn 2012;60:135-59.

91. Nash MR, Tasso A. The effectiveness of hypnosis in

Cite this article as: Facco E, Casiglia E, Zanette G, Testoni I. On the way of liberation from suffering and pain: role of hypnosis in palliative care. Ann Palliat Med 2017. doi: 10.21037/apm.2017.04.07 reducing pain and suffering among women with metastatic breast cancer and among women with temporomandibular disorder. Int J Clin Exp Hypn 2010;58:497-504.

92. Montgomery GH, David D, Kangas M, et al. Randomized controlled trial of a cognitive-behavioral therapy plus hypnosis intervention to control fatigue in patients undergoing radiotherapy for breast cancer. J Clin Oncol 2014;32:557-63.

93. Butler LD, Koopman C, Neri E, et al. Effects of supportive-expressive group therapy on pain in women with metastatic breast cancer. Health Psychol 2009;28:579-87.

94. Marchioro G, Azzarello G, Viviani F, et al. Hypnosis in the treatment of anticipatory nausea and vomiting in patients receiving cancer chemotherapy. Oncology 2000;59:100-4.

95. Richardson J, Smith JE, Mccall G, et al. Hypnosis for nausea and vomiting in cancer chemotherapy: a systematic review of the research evidence. Eur J Cancer Care (Engl) 2007;16:402-12.

96. Benedetti F, Lanotte M, Lopiano L, et al. When words are painful: unraveling the mechanisms of the nocebo effect. Neuroscience 2007;147:260-71.

97. Colloca L, Benedetti F. Nocebo hyperalgesia: how anxiety is turned into pain. Curr Opin Anaesthesiol 2007;20:435-9.

98. Colloca L, Finniss D. Nocebo effects, patient-clinician communication, and therapeutic outcomes. JAMA 2012;307:567-8.

99. Facco E, Manani G, Zanette G. The Relevance of Hypnosis and Behavioural Techniques in Dentistry. Contemporary Hypnosis 2013;29:332-51.

100. Facco E, Stellini E, Bacci C, et al. Validation of visual analogue scale for anxiety (VAS-A) in preanesthesia evaluation. Minerva Anestesiol 2013;79:1389-95. 